\title{
Development and anthropological fieldwork: Towards a symmetrical anthropology of inter-cultural relations
}

\author{
By Chris Campregher (University of Vienna)
}

\begin{abstract}
This text reflects on the recent science and technology studies (STS) turn in the anthropology of development. It highlights the similarities between the practice of development cooperation and ethnographic fieldwork. There has been considerable influence of STS in the post-millennium anthropology of development. How do STS and STS-inspired development studies contribute to the broader disciplinary development of anthropology? Based on contributions and concepts from Science and Technology Studies, I argue that the study of development helps us to understand our own knowledge and practice by observing how we engage with other people. The methodological principles and concepts presented in this text allow us to study inter-cultural relations symmetrically, including the researcher and his/her actions.
\end{abstract}

\section{Introduction}

In the study of rural development we usually distinguish institutions and professionals in donor and developing countries from so-called target groups or beneficiaries of development projects or interventions. Even as a trained anthropologist sensible to questions of ethnocentrism and cultural alterity, I relied on this basic imagery of the poor and marginalized when I started to work for the first time in Central America. How not to? Engaging in development work implies that there will be some class of people who need support of some kind. Even the conceptual and linguistic shift from "development aid" to "development cooperation" and corresponding discourses of participation and empowerment do not change the principle distinction of donors and recipients on which the very idea of development cooperation relies. There is always some kind of technology ${ }^{1}$ or resource that is transferred from the north to the south, from one culture to another, or from an institution to a local group.

When I went to Costa Rica in 2004 to work as a volunteer for a local NGO, I was immediately told that, firstly, I should learn from the peasant families and small farmers I would work with. Second, they would not need any help or support I could provide. Later, a colleague taught me that it takes about half a

1 Technology to be transferred includes not only material aspects but also non-material ones such as models of democracy, civil society, organisational technologies, among others. 
year until one "discovers" an aspect of village life where one may help. Realising this, he designed a small cooperative project based on the construction of a small house to accommodate tourists and volunteers. Nevertheless, by the fourteenth month local people did not perceive any of us Europeans working for the NGO as people who would support them in any way. Rather, we were seen as visitors with plenty of time to visit the villages and eager to design some kind of community project.

About a year and a half later, after having returned to Austria, I started field research for my master's thesis about a planned dam in the same region. My research focused on the relationship between an indigenous community affected by the development and the agency that developed the dam. I interviewed and observed both the rural village and agency staff, who were sociologists and anthropologists like myself. Most of the spokespersons for the village community were against the construction of the dam. Nevertheless, in the opinion of the social scientists that promoted the dam, the locals were against it only because they were badly informed when, "in reality", the construction would bring them benefits. Soon, I found the same pattern of motivation and professional self-representation among development agents. In particular, Carlos ${ }^{2}$, a young anthropologist I made friends with, enthusiastically searched for a way to "help" the community with some of their concerns and tried to channel resources towards this aim.

In 2009 I interviewed professional staff of environmental and conservationist NGOs in San José, Costa Rica. Again, the same pattern and imagery appeared. Although the conservationist NGOs' staff represented its agencies' concerns to protect the environment, all of them were convinced that they could support local communities to achieve more sustainable lifestyles. At the same time, many of these communities, especially indigenous ones, mistrusted governmental and non-governmental organisations' strategies because of the restriction they imposed on the use of natural resources.

About the same time, I was involved in the design of a collaborative research project by a Central American University and a European NGO. We approached an indigenous community which is located on the border to a prominent national park. In the past they have had very conflicting relationship with the reserve administration and environmental NGOs. So we proposed that their spokespersons worked towards the integration of their priorities in regional strategies for conservation. But their response fitted the same pattern. In our first attempt the spokespersons of the community refused to work with us. They argued that they would not need support in the comanagement of an area which they already had been using in a sustainable manner for decades.

What do these examples show us? First, in these cases, institutions aim to improve the situation of a local population in some way or the other; whether by supporting sustainable development or by promoting the conservation of natural resources. Second, people who work in these organisations are

2 Name changed by the author. 
convinced that they can help the local population. This, in turn, implies that they think these communities lack something or require some kind of support. Third, the target groups do not perceive the agencies and their promoters in the same way. In their view, these agencies have agendas different from their own.

Now, as some of the articles published in a recent edition of this journal indicate (Pickering 2009, Walker 2009), the disparities of the perception of an interaction between persons from different socio-cultural contexts are not restricted to the practice of development. Rather, they are a more common feature of intercultural interaction as in the form of anthropological fieldwork. In this article, I want to ask if there is a theoretical foundation or a methodology that allows us to document these different perceptions and representations. If we can answer this with a "yes", then this methodology may be relevant for the practice of ethnographic fieldwork and anthropology as a whole.

\section{Symmetry}

In the $19^{\text {th }}$ century, in the midst of European modernity, anthropology was born as a discipline that sought to study exotic cultures that were different from the ones of its practitioners. Today, anthropologists study not only these cultural "others" but also their own societies. Much of this "anthropology at home" focuses on subaltern groups on the margins of our post-modern societies or on its subcultures. Nevertheless, while we question and explain what we find in the field through the use of anthropological concepts and theories, we hardly study ourselves and our actions as anthropologists with the same methods (methodological agnosticism). Only in recent years have anthropologist influenced by Science and Technology Studies (STS) started to produce ethnographies of the central institution of our post-modern societies including anthropology as an academic discipline. There has been considerable influence of STS in the post-millennium anthropology of development. Why has this been the case? How do STS and STS-inspired development studies contribute to the broader disciplinary development of anthropology?

Science and Technology Studies is the name of a heterogeneous sub-field of sociology whose practitioners apply conventional sociological and anthropological methods such as interviews, observation, and text analysis in order to study the practice of scientific labour and technological innovation (Bloor 1991). Over the course of recent decades, researchers of science and technology have established some principles of symmetry in order to avoid asymmetrical studies, i.e. ones that treat science differently from other mundane practice.

Rottenburg (1998: 62-4) adopts these principles for anthropology and summarises them as follows: a symmetrical methodology applies the same language to (1) right and wrong statements (truth and errors; knowledge and belief), (2) human beings and material objects (in order to overcome the 
nature-society divide), (3) western and non-western societies, and (4) anthropological and non-anthropological practice. The anthropologist should treat them in the same way and explain them by using the same concepts. An anthropology based on these principles of symmetry promises to overcome not only the modern western idea which conceptualizes nature and society as two distinct spheres, but also the grand divide between modern and primitive or premodern societies by framing them as collectives that integrate a different number of human and non-human beings and which construct their cosmologies around them (Latour 1993). This is one of the reasons why STS, and especially Actor-Network Theory as promoted by the half-anthropologist Bruno Latour, are increasingly relevant for the anthropological study of development (Lewis \& Mosse 2006; Mosse 2005; Rottenburg 2009; Weilenmann 2005).

What does that mean for the study of development and anthropology as a discipline? Development projects are very similar in their structure to scientific experiments and field research. The managers of these interventions construct and explore reality in a place far away from the bureaucratic centres which finance these activities. They have developed a series of methods, i.e. the logical framework-model, in order to "grasp" these realities by transforming them into written representations. First, development agents learn about a region and their characteristics with the help of existing representations (books, reports, maps, among others) or the production of new ones ("fact-finding missions"). Then, they define a specific problem based on a set of more or less well-founded knowledge and assumptions. Next step is to design a methodology and a plan of how to treat this problem. Expected results are formulated as well as risks or sources of failure. Finally, in the course of the project's execution, agents have to struggle with all the different elements (human and non-human factors) of reality where the plan is to be put into practice. Agents and managers simultaneously engage in the project's activities and its representation on a discursive level as expressed in reports and documents (Mosse 2005). At the same time, development cooperation relies on the basic idea that there exist technologies or models that are scientifically tested and universally valid, so they just need to be transferred to developing countries (Rottenburg 2009). Therefore, I think development cooperation and science are related on two levels; their structural similarity and the legitimization of the first through the last.

The interesting question that STS poses to us as anthropologists is the following: STS scholars state that they need to treat science and its outcomes ("scientific facts") with the same methodological scrutiny that they use to explain "wrong" statements. So, how can development agents and anthropologists continue to differentiate between scientifically legitimized "knowledge" and culturally constrained "beliefs" of local communities? ${ }^{3}$ In

3 As an anonymous reviewer suggested, in relation to anthropology in general it would be interesting to compare the ways in which anthropologists have traditionally addressed questions of the veracity of beliefs (e.g. Evans Pritchard) and why anthropologist's cultural relativism has still been different from the symmetrical approach I argue for. 
other words, as a practitioner of development cooperation I help to transfer technology and cultural representations from one part to the world to another. But as an anthropologist, I need to treat these scientifically legitimated representations in the same way I treat the cultural representations of rural communities. This tricky question and the related professional schizophrenia faced by us who are committed simultaneously to development cooperation and anthropology are reflected in recent ethnographies of development projects (Campregher 2010, Mosse 2005; Rottenburg 2009). Although this question poses itself more directly in the anthropology of development, I think in some way or the other it is relevant for any kind of anthropological research. Somehow we must try to work symmetrically. 


\section{Towards a symmetrical anthropology? Three examples and some considerations}

Anthropologists of development pursue different strategies in order to avoid asymmetrical accounts in their ethnographies. Because of limitations of space, I will only present four short examples of accounts which adopt such symmetrical approaches. For the same reason, I will not review a large number of publications in a systematic manner. Rather, I want to invite the reader to look for other examples, or even to develop their own accounts of symmetrical ethnographies by experimenting with some of the concepts I will explore in more detail later on. All of the following case studies draw on different concepts and ideas expressed in ANT studies. Their authors experiment with them in the context of the anthropology of development.

In a study of a project that aimed to improve the waterworks of a sub-Saharan country, Rottenburg (2009) fictionalizes his account. Although based closely on the author's experiences working on and observing different development projects in the 1990s, this is a novel-like story in which an anthropologist from Normland looks for what is going on "inside" the development cooperation. He starts with interviewing bureaucrats from the donor agency, a Normasian development bank, and the staff of a consultant firm. Later the hero of our ethnographic story accompanies the consultant's staff to Ruritania where the project is to be implemented. Rottenburg combines a narrative approach and the ethnographic description with theoretical reflection using concepts from organization studies, STS, and post-structural anthropology. But the most interesting feature of this monograph is that Rottenburg positions himself (an anthropologist working for the consultant firm) inside the story. That allows the author to describe his own actions and representations as if he would have observed and interviewed himself, the consultant anthropologist.

Mosse (2005) provides an ethnography of a British-Indian Rainfed project that is more conventional in its textual presentation but not less innovative in its application of STS-concepts. Studying the project and its policy documents as actor-networks, he starts by posing a simple question in a new way. What if development practice is not driven by policy? What if policy which mobilises political support and financing, does not necessarily facilitate its implementation in practice? By studying this project in western India over more than ten years as it falls under different policy regimes, Mosse draws light on the obscure relationship between policy and practice. He explains in detail how the actions of development agents are shaped not primarily by policy, but by the exigencies of organisations. Nevertheless, he concludes that policy is important in the way that all of the actors in the study work hard to maintain representations in order to present their actions as authorised policy.

The third example is my own study on a hydro electrical dam and its conflicts with an affected indigenous community, I already mentioned above (and published in Campregher 2008, 2010). In these texts, I argued that we get a clearer idea of what is going on in a situation if we recognise that each category of social actor involved (dam developers, indigenous activists, and the anthropologist), both brings and generates a different perspective. We can 
describe each actor's representations by shifting the observer's perspective. What do I mean by "shifting the perspectives"? Every account of reality not only depicts reality, but always orders the way in which we perceive it. As a consequence, every representation has its blind spot: it cannot observe either its own position or its own differentiations and classifications (Rottenburg 2009). If we cannot get rid of the blind spots, at least we can try to place them differently. Therefore in the study of the dam, I illustrated the representations of the actors or actor groups as they were given by them, drawing on documents and interviews that represent each perspective in the actors' own original terms. Following this, the viewpoint of the researcher was treated and presented in the same way as the non-sociological accounts.

Weilenmann (2005) uses "chains of translations", another ANT concept, in order to explain donor-target group relations in a project in Rwanda. In development cooperation a huge number of elements are constantly crossing an indefinite number of virtual boundaries, may they be political, social, cultural, or ontological. Tracing these chains of translation like Weilenmann does, allows us to draw light on the transnational processes by which target populations such as poor women in Rwanda are connected to private donors in Europe. In order to bring the first to the last they need to be translated into transportable cultural representations (a change from physical reality into signs), before they are related and translated by various mediators such as African women's rights groups and European NGOs. In every part of this chain, the elements that pass it are reduced and amplified according to the specific necessities of each station, before they eventually succeed in motivating people and institutions in wealthier countries to donate. The notion of chains of translation not only serves to trace these connections, it also avoids the erroneous conceptualisation of the local and the global as two distinct dichotomous spheres.

Limiting myself to these examples, I want to motivate everyone to experiment with ways that allow us to produce more symmetrical ethnographic studies. These different accounts provide just a few concepts, such as the fictionalisation and the novelization of our ethnographies (Rottenburg), the long-time study of projects in which we are professionally involved (Rottenburg, Mosse), the addressing of disparities between discourse and practice (Mosse), the shifting of perspectives in the text (Campregher, Rottenburg), or the use of concepts such as chains of translation that allow us to trace the actors and the action in the field (Weilenmann). The triangulation of methods based on participant observation, interviews and the analysis of documents and reports is another important aspect. Triangulation of methods and of perspectives allows us to study the discursive level and the practice of what is going on between the actors in the field including the anthropologist.

\section{Studying interaction as chains of relations}

When an anthropologist or a development extensionist approaches a rural community, there are always at least three elements: a subject (development agent, anthropologist, etc.), a group of people ("the locals") that represents 
the object, and some kind of mission. By mission I mean the reason for the interaction and the motivation of the subject. For an anthropologist, the mission could be to describe the group of people that constitute the object. For a development worker (or a related NGO) it could be to support them through the transfer of resources and knowledge. In the field, we can experiment and literally feel the importance of some kind of mission or motivation for fieldworkers, if, for some reason, we do not have one. Imagine going to a rural village in i.e. Rwanda for your thesis. After finishing and writing up your study, how long will you be willing to stay there without having any further research or professional interest?

Now, I suggest, that the anthropologist's mission and her/his motivation is based on a meta-narrative of ethnographic fieldwork. By this I mean, the narrative of the lonely fieldworker who explores a foreign culture and translates it into another, to put it in a very simple manner. Although most of us might be aware of the romantic misconceptions of this narrative, I think, unconsciously, it helps us to maintain our motivation and to justify to ourselves what we are doing.

In the case of professional extensionists, there exists a development narrative that structures the extensionists' representation in the same way: It establishes the same distinction between subjects, objects, and mission. As indicated by the above examples from my own experience, the mission is to "help" or "support" other people.

\section{Chain of Translation}

The Development Situation: Development
Workers

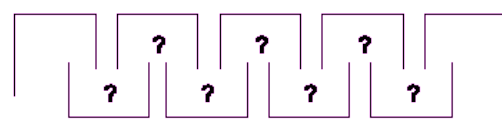

Locals

The Fieldwork Situation:

Anthropologist

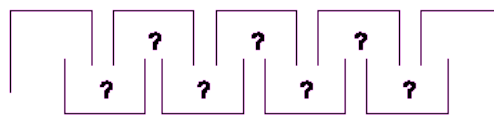

Locals

Figure 1: Information that flows along the chains of translation is translated in accordance with the mission of each station: locals, their representatives, and the development worker/the anthropologist. Question marks represent 
information or knowledge that is transformed in form (i.e. spoken statements into texts) translated by the actors.

Project policy documents are specific variations of the general development narrative that serve as a framework for the individual's mission. As Mosse (2005) argues, these accounts serve to legitimise the intervention and to gain political support. But they do not necessarily provide us with a reliable account of what is going on between the actors in the field. The same, I suggest, applies for academic studies and monographs. They are written for an academic audience and relate to specific theoretical problems and discussions. In symmetrical approaches we may include the production of these texts into our accounts by analysing the interaction between the subject and the object as a chain of translation (fig. 1).

In the aforementioned case study of the dam, I interviewed anthropologists and sociologists who work for the planning agency. They contact the indigenous communities in order to inform them about the project and to learn about the characteristics of its population. It is these social scientists' task to translate the project's plans into more specific statements and to find answers to the questions of worried farmers and ambitious community leaders. This is their overall mission, the one which guides the translations of information and representations in the chains of translations that relate the local reality with the project plan. The development workers translate them in meetings, texts, and discussions with local leaders. Simultaneously, the indigenous leaders use these events to mobilise political support among the community. They translate the information provided. At the same time, they formulate statements that resume the opinion of a larger number of community members. 
When we begin to study such interactions, there are at least two objects already present in the field: the development agents and the locals. With our arrival on the scene the anthropologist becomes the subject. How can we study, the interaction between the anthropologists and his or her object(s) and, at the same time, the relation between both groups as they inter-ACT? A symmetrical approach studies the chains of translation that relate both (or multiple) actor's, and the ones by which the anthropologist relates to them (fig.

\section{A Symmetrical Approach}

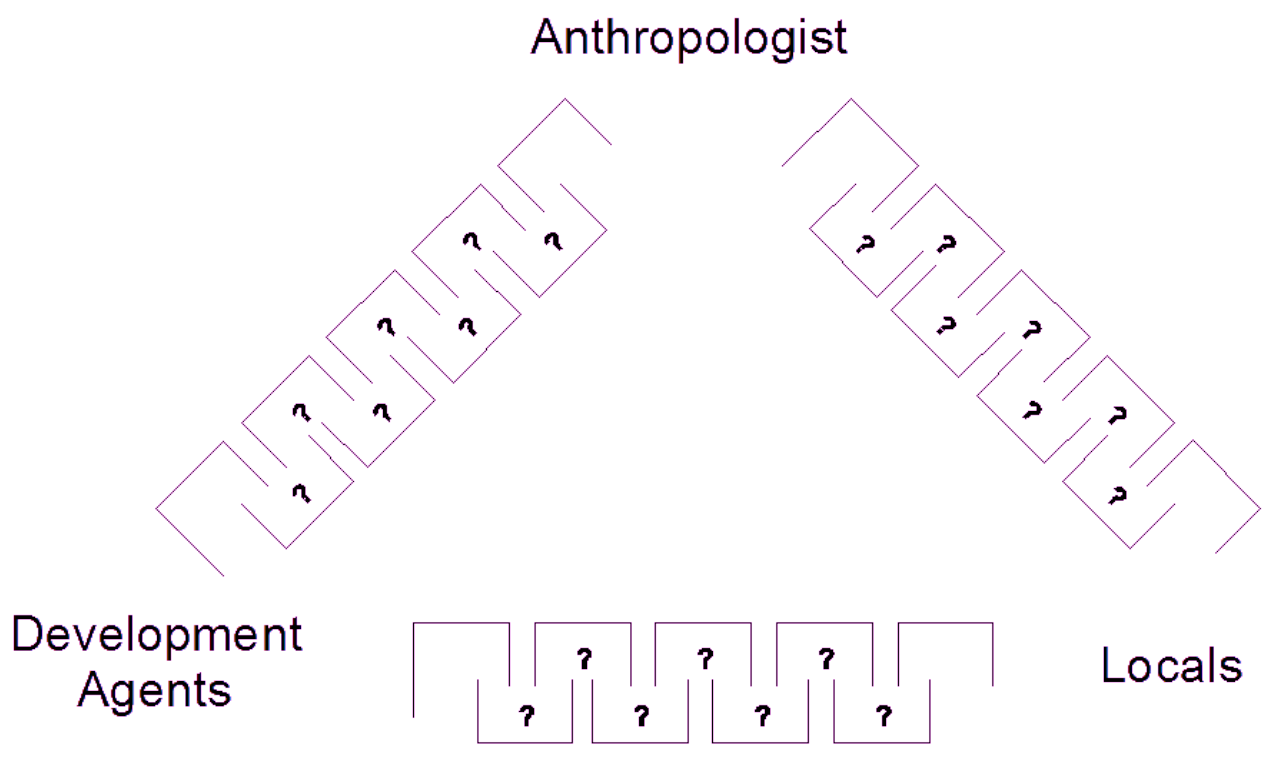

2).

Figure 2: A symmetrical anthropology studies not only the chains of translation between actors in the field but include the anthropologist and his methods.

In the fieldwork setting of the aforementioned study, I participated in meetings and met local leaders and activists that were against the construction of the dam, and others that were more willing to support it. I talked to persons who I believed to be key actors, or more generally, who seemed to know more about the project than the average villager. Together with related observations, their statements were compared to other studies with the aim of identifying contradictions or similarities. Based on this method I formulated generalizations and statements in the language of our discipline. At the beginning of the journey my aim was to study the community and to transform this experience into a scientific text. Nevertheless, every contact I made and every interview I undertook changed my interest and the outcome of my study. At the end of this process the original interest was associated with those of a series of actors, who influenced the course of my investigation. It has been transformed and translated (Callon \& Law 1982). Analysing what supporters and opponents of the dam have in common, one could say that their common 
motivation despite conflicts and divergent opinions was to establish themselves as brokers and translators (Lewis \& Mosse 2006) between the rest of the population and the agency. By receiving me and by answering my questions the leaders, I addressed, strengthened their position as spokespersons for the community and their kin group.

\section{Conclusions}

As committed but critical and self-reflexive individuals working in the field of development cooperation, students and early-career anthropologists will inevitably be confronted with some basic contradictions, which they soon notice, are not singular events due to individual failure or unlucky constellations. Rather, these contradictions seem to be basic characteristics of inter-cultural cooperation and the interaction of agencies and local populations. The obvious gap between resources and possibilities of so-called partners from different socio-cultural contexts and their disparately different motivations as well as the contradictions of projects' self-representations and their practice are just some of the dimensions of which we need to be aware as anthropologists of development.

In this text, I reflect on a recent science and technology studies turn in the anthropology of development which expresses itself, first, in an increasing awareness that the anthropologist is part of the field settings in which these studies are realized, and second, in new creative methodologies and genrebreaking forms to present ethnographic texts. My own intention is to contribute to this turn by drawing on the concept of chains of translations which I illustrate here through the example of a recent study. According to my interpretation of the science and technology ttudies turn anthropology should strive to become more symmetrical. That means that we should question and study our own methodologies, concepts, and actions in the field and on the desk in the same way we study our informants. This, I think, will not only lead to a new way of looking at the anthropologist as an actor in the field, but also represents a strategy favourable to those of us who work as applied anthropologists. Working in agencies, firms, governmental and nongovernmental organisations or as consultants is a form of participant observation that is hardly discussed in academic anthropology. But it is this type of commitment to the field which constitutes the majority of STSinfluenced development studies. In the same manner, I suggest, we can study other forms of inter-cultural communication or knowledge/resource-transfer between institutions and populations.

\section{About the author}

Chris Campregher is currently writing his doctoral thesis at the University of Vienna, Austria. He is based in Costa Rica and works there in an applied "research for development" project on biocultural diversity for the University of 
Costa Rica with the indigenous Ngöbe-Buglé on the border to Panama and as consultant for environmental NGOs. He is particularly interested in the study of development and intercultural relations, Actor-Network Theory, natural resource management, tropical ecology and the use of plants. The author can be contacted at campregher@gmx.at 


\section{References}

Bloor, D. 1991 [1976]. Knowledge and Social Imagery. Second edition with a new foreword. Chicago.

Callon, M. and J. Law. 1982. On Interests and Their Transformation: Enrolment and Counter-Enrolment. Social Studies of Science 12(4):615-625.

Campregher, C. 2008. Perspektivenwechsel: Drei Paradigmen der Entwicklungsanthropologie und die Akteur-Netzwerk-Theorie. Austrian Studies in Social Anthropology 2008(3):1-29.

Campregher, C. 2010. Shifting Perspectives on Development: An actornetwork study of a dam in Costa Rica. Anthropological Quarterly (in print / accepted).

Latour, B. 1999. Pandora's Hope: An Essay on the Reality of Science Studies. MA/London: Harvard University Press.

Latour, B. 1993. We Have Never Been Modern. New York: HarvesterWheatsheaf.

Latour, B. 2005. Reassembling the social. An introduction to Actor-Network Theory. Oxford: Oxford University Press.

Lewis, D. and D. Mosse, eds. 2006. Development Brokers and Translators. The ethnography of aid and agencies. Bloomfield. CT: Kumarian Press.

Mosse, D. 2005. Cultivating Development: An ethnography of aid policy and practice. London: Pluto Press.

Pickering, L. 2009. Dancing my true dance: reflections on learning to express myself through ecstatic dance in Hawai'i. Anthropology Matters Journal 11(1).

Rottenburg, R. 1998. Towards an Ethnography of Translocal Processes and Central Institutions of Modern Societies. In Aleksander Posern-Zielinski, The Task of Ethnology. Cultural Anthropology in Unifying Europe, pp. 59-66. Poznań: Wydawnictwo Drawa.

Rottenburg, R. 2009. Far-Fetched Facts. A Parable of Development Aid. Cambridge, Mass.: MIT Press.

Walker, M. 2009. Priest, development worker, or volunteer? Anthropological research and ascribed identities in rural Mozambique. Anthropology Matters Journal 11(1). 
Weilenmann, M. 2005. Ist Projektrecht ein Erfüllungsgehilfe von Organisationen der Entwicklungshilfe? Eine Fallstudie aus Burundi. In Entwicklungsethnologie 14(1-2):129-148. 